\title{
Silencing of Rape: Treatment of Rape Events and Rape Victims by Media and Fiction
}

\author{
SHAHID AHMAD \\ SHANTHI NADARAJAN \\ AHMED SHAMSUL BAHARI \\ Universiti Malaysia Sarawak
}

\begin{abstract}
Sexual abuse affects over 120 million children globally (UNICEF, 2018). There has been a total of 48 , 338 cases of rape of minors in India, with an increase of 336\% from 2,113 in 2001 to 7,112 in 2011 (Gohain, 2013). In the US, almost half of female victims (46.7\%) had been raped by an acquaintance (Breiding, 2014), with assaults (55\%) occurring at or near the victim's house (Planty \& Langton, 2013). Each time a rape victim dies, there is public outcry with both press and writers' calling for action but this has not helped the cause. Largely because "rape is not just forcible intercourse; rape means to inhabit and destroy everything" (Sebold, Lucky, 2002). This research analyses headlines and quotations on sexual crimes from mainstream online news from 2018 to 2019 from India and Malaysia. Using Austin's Speech act theory, the study compares the voices of rape victims and witnesses and argues for a reason and social responsibility. The findings revealed significant differences in discourse patterns, language use, and witness response. In providing a worm's eye view, Indian press in appearing to speak louder for victims, create greater sensationalism compared to Malaysian press which often focuses on the culprit and process of law and quickly silences the matter. Given media sensationalism and agenda setting of both nations, there is the need for greater scrutiny on how media provides a voice to victims and helps raise awareness and social responsibility when reporting sexual crimes.
\end{abstract}

Keywords: Women, rape survivors, trial by media, voicing, stylistic analysis.

\section{INTRODUCTION}

It is said that "...for every survivor there is also a rapist" (Bode, 1990, p.40). Nothing could be further from the truth here. Rape is a horrific crime due to loss of power for both victim and perpetrator. The American writer and healer, Deena Metzger calls rape 'depersonalization' (1976); the action of divesting someone or a state in which one's thoughts and feelings seem unreal or not belong to oneself. Weis and Borges (1973) point out that "rape is a total attack against the whole person, affecting the victim's physical, psychological and social identity" ( $p$. 72). Rape, therefore, serves as an indispensable constituent of the victim's personality and life. Sociologist-cum-feminist, Kathleen Barry explains in Female Sexual Slavery that where there is an attempt to separate the sexual experience from the total person, the first act of objectification tends to be perversion (2011). What is sad is that many of the myths on sexual violence and women asking to be raped are partly fuelled by media reporting. No woman deserves to be raped or abused and the media has a role in raising this awareness.

As stated by Verghese (2018), "media ethics and social responsibility have always been important but never so much as today". This is because knowledge is power and in the wrong hands, it can create havoc for the wronged. The communication revolution has ushered in within a lifetime, the computer and the internet which in turn has paved the way for the Web that is able to create an instant world that has shrunk in space and time. The rise of 